CLINICAL STUDY

\title{
Hypercholesterolemia, eligibility for lipid-lowering therapy and therapeutic success: population-based study in a Portuguese urban population
}

\author{
Luis Alves ${ }^{1,2}$ and Ana Azevedo ${ }^{1}$ \\ ${ }^{1}$ Department of Hygiene and Epidemiology, University of Porto Medical School, Institute of Public Health, University of Porto (ISPUP), Alameda Prof. \\ Hernani Monteiro, 4200-319 Porto, Portugal and ${ }^{2}$ Santo André de Canidelo Health Family Unit, 4400-230 Vila Nova de Gaia, Portugal \\ (Correspondence should be addressed to L Alves; Email: pdsp07011@med.up.pt)
}

\begin{abstract}
Background: We aimed to estimate i) the prevalence of hypercholesterolemia, ii) the proportion of individuals eligible for treatment with lipid-lowering drugs, and iii) therapeutic success, according to the European guidelines on cardiovascular disease prevention in clinical practice.

Design: Population-based cross-sectional study.

Methods: We surveyed a representative sample of the population of Porto aged 40-65 years. Trained interviewers collected data from 1215 subjects (789 women) on demographic variables, medical history, and medication using structured questionnaires. A fasting venous blood sample was withdrawn. Subjects were considered low risk or high risk as indicated in the European guidelines. Hypercholesterolemia was defined as total cholesterol (TC) $\geq 5 \mathrm{mmol} / \mathrm{l}$ or low-density-cholesterol (LDL-C) $\geq 3 \mathrm{mmol} / \mathrm{l}$ in low-risk subjects, TC $\geq 4.5 \mathrm{mmol} / \mathrm{l}$ or LDL-C $\geq 2.5 \mathrm{mmol} / \mathrm{l}$ in high-risk subjects or being medicated with lipid-lowering drugs. Eligibility for treatment was defined as being high risk and having TC $\geq 4.5 \mathrm{mmol} / \mathrm{l}$, LDL-C $\geq 2.5 \mathrm{mmol} / \mathrm{l}$ or being on treatment. We defined therapeutic success as having TC $<4.5 \mathrm{mmol} / \mathrm{l}$ and LDL-C $<2.5 \mathrm{mmol} / \mathrm{l}$ among medicated subjects.

Results: Overall, $84.9 \%$ (95\% confidence interval (95\% CI): 82.7-86.8) of subjects had hypercholesterolemia and 9.1\% (95\% CI: 7.5-10.8) were medicated with lipid-lowering drugs. Men were more likely to be eligible for treatment $(42.4 \%)$ than women $(22.4 \%$; OR $=2.69$, 95\% CI $2.07-$ $3.52)$. Therapeutic success was less frequent in men $(46.8 \%)$ than in women $(66.7 \%),(\mathrm{OR}=0.39$, 95\% CI 0.17-0.87).

Conclusion: Strict interpretation of the European guidelines would label 85\% of the general population in this age group as hypercholesterolemic and a third eligible for drug treatment. Questions arise regarding medicalization, resource allocation, and sustainability within the healthcare system.
\end{abstract}

European Journal of Endocrinology 159 755-760

\section{Introduction}

Cardiovascular diseases (CVD), particularly those of atherosclerotic etiology, are the leading cause of morbidity and mortality in Portugal, both in men and women (1). In 2005, diseases of the circulatory system accounted for $34 \%$ of all deaths (2).

In the last decade, there has been a clear trend toward a more intensive approach on low-density cholesterol (LDL-C)-lowering therapy. Meta-analyses of clinical trials with lipid-lowering drugs documented relative risk reductions of $25 \%$ (3) and $19 \%$ (4) for coronary events and non-hemorrhagic cerebrovascular events respectively. Reductions in LDL-C levels of up to $35 \%$ can be achieved with maximal dietary therapy (5).

CVD risk assessment has become an important tool in the primary prevention of these diseases (6). The Framingham Heart Study provided data for the first and most widely used risk prediction tool $(7,8)$. However, this equation overestimated coronary heart disease (CHD) and CVD risk in the European populations, particularly in those considered at low risk (9-13). In 2003, the Third Joint Task Force of European and other societies on Cardiovascular Disease Prevention in Clinical Practice recommended the use of the SCORE (14) function in the management algorithms of the European guidelines on cardiovascular disease prevention in clinical practice (15). In the recent update (6), SCORE remains the tool of choice for the prediction of the 10-year risk of fatal CVD.

In this study, we intended to determine i) the prevalence of hypercholesterolemia, ii) the proportion of individuals eligible for treatment with lipid-lowering drugs, and iii) the proportion of individuals on treatment for hypercholesterolemia with desirable lipid profiles, according to the European guidelines on CVD prevention in clinical practice. 


\section{Methods}

We designed and conducted a cross-sectional study on a representative sample of community dwellers of Porto aged 18 years or older. We used random digit dialing of landline telephones to select households. At the time of this procedure, most houses had a landline telephone. Assuming the local prefix codes to constrain the universe to the city of Porto, we used a table of random numbers to define the last four digits that are specific to individual houses. Non-existing numbers, those corresponding to fax numbers or telephone numbers of nonindividual subscribers (companies, institutions, and so on) were disregarded. We assumed the number was unreachable and disregarded it after at least four attempts at different hours and including week and weekend days. Using simple random sampling we selected one eligible subject within each household. Eligible subjects were all permanent residents aged $\geq 18$ years. Refusals were not substituted within each household. The proportion of participation was $70 \%$. (16). Data were collected between 1999 and 2003. Within this cohort, subjects aged between 40 and 65 years were eligible for the current analysis $(n=1402)$. We excluded 187 subjects with incomplete data on smoking habits, systolic blood pressure, total cholesterol (TC) or LDL-C. There were no significant differences between excluded and included subjects regarding sex, age, education, body mass index, smoking status, and self-reported hypertension, diabetes and dyslipidemia.

Trained interviewers collected data on demographic variables, past medical history and medication using structured questionnaires. A 12-lead resting electrocardiogram was registered. A fasting blood sample was collected from all subjects. Serum glucose level was determined using routine enzymatic methods, and cholesterol and triglyceride levels were determined using standard enzymatic colorimetric methods $(17,18)$. High density lipoprotein cholesterol levels were determined after precipitation of apolipoprotein B-containing lipoproteins (19). LDL-C levels were calculated using the Friedewald function (20). Personal history of CVD was considered according to the self-reported information on previous myocardial infarction, angina pectoris or stroke, or the presence of $Q$ waves on the electrocardiogram. Diabetes mellitus was defined as fasting blood glucose levels $\geq 7 \mathrm{mmol} / \mathrm{l}(\sim 126 \mathrm{mg} / \mathrm{dl})$ or being medicated with insulin or oral anti-diabetic agents.

We computed the 10-year risk of death from cardiovascular disease using the low-risk function of the SCORE project (14). Subjects were classified as high-risk a priori if i) there was personal history of previous cardiovascular disease, ii) they were diabetic, or iii) they had TC levels $\geq 8 \mathrm{mmol} / \mathrm{l}(\sim 320 \mathrm{mg} / \mathrm{dl})$ or LDL-C levels $\geq 6 \mathrm{mmol} / \mathrm{l}$ $(\sim 240 \mathrm{mg} / \mathrm{dl})$. A predicted 10-year risk of death from CVD $\geq 5 \%$ (using the age projected to 60 years old in subjects aged $40-60$ years or the real age in participants older than 60 years) was used to define high risk in the remaining subjects. As recommended by the European Guidelines on Cardiovascular Disease Prevention on Clinical Practice (6), subjects were considered to have hypercholesterolemia if they were in the low-risk group and had TC levels $\geq 5 \mathrm{mmol} / \mathrm{l}$ $(\sim 190 \mathrm{mg} / \mathrm{dl})$ or LDL-C levels $\geq 3 \mathrm{mmol} / \mathrm{l}(\sim 115 \mathrm{mg} / \mathrm{dl})$ or if they were in the high-risk group and had TC levels $\geq 4.5 \mathrm{mmol} / \mathrm{l}(\sim 175 \mathrm{mg} / \mathrm{dl})$ or LDL-C levels $\geq 2.5 \mathrm{mmol} / \mathrm{l}(\sim 100 \mathrm{mg} / \mathrm{dl})$. We considered subjects already medicated with cholesterol-lowering drugs as having hypercholesterolemia. Eligibility for treatment with lipid-lowering drugs was defined as being high risk and having fasting TC $\geq 4.5 \mathrm{mmol} / \mathrm{l}(\sim 175 \mathrm{mg} / \mathrm{dl})$ or LDL-C $\geq 2.5 \mathrm{mmol} / \mathrm{l}(\sim 100 \mathrm{mg} / \mathrm{dl})$ or being on medication. We defined controlled hypercholesterolemia as TC $<4.5 \mathrm{mmol} / \mathrm{l}(\sim 175 \mathrm{mg} / \mathrm{dl})$ and LDL-C $<2.5 \mathrm{mmol} / \mathrm{l}$ $(\sim 100 \mathrm{mg} / \mathrm{dl})$ in treated subjects. Optional more stringent thresholds, TC $<4 \mathrm{mmol} / \mathrm{l}(\sim 155 \mathrm{mg} / \mathrm{dl})$ or LDL-C levels $<2 \mathrm{mmol} / \mathrm{l}(\sim 80 \mathrm{mg} / \mathrm{dl})$, are also considered in the guidelines (6). Data were also analyzed for these cut-off values. In our study, we defined the first set of target lipid levels as 'primary goal' and the second set as 'secondary goal'.

\section{Statistical analysis}

Descriptive data are presented as count (\%) for categorical variables and median (interquartile range) for non-normally distributed continuous variables. Exceptionally, for the sole purpose of comparison with previously published data, mean, and S.D. are also reported for the 10-year fatal CVD risk, despite its skewed distribution. Comparison between groups was made using the Mann-Whitney test when the variables did not follow a normal distribution. Prevalence was compared between genders using the $\chi^{2}$-test. Logistic regression modeling was used to compute odds ratios (OR) and 95\% confidence intervals (CI) to quantify associations between the different outcome variables and covariates. After observing a linear association between hypercholesterolemia, eligibility for treatment and therapeutic success (outcome variables), and age (independent variable), ORs for the effect of age were computed using the continuous variable.

\section{Results}

Table 1 depicts the characteristics of the study sample. Smoking was significantly more prevalent among men $(P<0.001)$. Dyslipidemia was self-reported by $37.5 \%$ (95\% CI: 34.7-40.2) of subjects and there was no gender difference $(P=0.70)$. There was no difference in the remaining variables used to compute CVD risk estimates. Out of the 1215 subjects, 198 (16.3\%) fulfilled at least one criterion to be considered a priori in the high-risk group (83 were diabetic, 85 had previous personal history of CVD, 52 had TC levels above $8 \mathrm{mmol} / \mathrm{l}(\sim 320 \mathrm{mg} / \mathrm{dl})$ and 
Table 1 Sample characteristics according to the gender.

\begin{tabular}{|c|c|c|c|}
\hline & Women $(n=764)$ & Men $(n=451)$ & $\boldsymbol{P}$ \\
\hline Age, years & $52(46-58)$ & $52(46-59)$ & 0.60 \\
\hline Education, years & $6(4-12)$ & $9(4-12)$ & $<0.001$ \\
\hline Systolic blood pressure, $\mathrm{mmHg}$ & $130(120-145)$ & $130(120-146)$ & 0.22 \\
\hline Diastolic blood pressure, $\mathrm{mmHg}$ & $81(76-90)$ & $82(78-90)$ & 0.09 \\
\hline Hypertension $^{\mathrm{a}}, n(\%)$ & $370(48.4 \%)$ & $238(52.8)$ & 0.14 \\
\hline Total cholesterol, $\mathrm{mmol} / \mathrm{l}$ & $5.69(5.04-6.54)$ & $5.72(5.02-6.44)$ & 0.63 \\
\hline LDL cholesterol, $\mathrm{mmol} / \mathrm{l}$ & $3.62(3.00-4.28)$ & $3.72(3.05-4.32)$ & 0.17 \\
\hline HDL cholesterol, mmol/l & $1.50(1.27-1.76)$ & $1.24(1.06-1.45)$ & $<0.001$ \\
\hline Triglycerides, mmol/l & $1.10(0.79-1.56)$ & $1.36(0.94-1.98)$ & $<0.001$ \\
\hline Current smoker, $n(\%)$ & $126(16.5 \%)$ & $161(35.7 \%)$ & $<0.001$ \\
\hline Body mass index, $\mathrm{kg} / \mathrm{m}^{2}$ & $27.0(23.8-30.5)$ & $26.5(24.5-28.7)$ & 0.06 \\
\hline Diabetes $^{\mathrm{b}}, n(\%)$ & $45(5.9 \%)$ & $38(8.4 \%)$ & 0.09 \\
\hline Use of lipid-lowering drugs, $n(\%)$ & $63(8.3 \%)$ & $47(10.4 \%)$ & 0.22 \\
\hline Dyslipidemia $^{\mathrm{c}}, n(\%)$ & $283(37.0 \%)$ & $172(38.1 \%)$ & 0.70 \\
\hline Predicted 10 -year risk of cardiovascular death, $\%^{\mathrm{d}}$ & $0.4(0.2-1.1)$ & $1.5(0.8-3.5)$ & $<0.001$ \\
\hline High risk, $n(\%)^{\mathrm{e}}$ & $139(18.2 \%)$ & $178(39.5 \%)$ & $<0.001$ \\
\hline
\end{tabular}

Data are presented as median (interquartile range) for continuous variables and $n$ (\%) for categorical variables.

${ }^{a}$ Based on medication or diastolic blood pressure $\geq 90 \mathrm{mmHg}$ or systolic blood pressure $\geq 140 \mathrm{mmHg}$.

${ }^{\mathrm{b}}$ Based on self-report or fasting glucose $\geq 126 \mathrm{mg} / \mathrm{dl}$.

'Based on self-report.

${ }^{\mathrm{d} D a t a}$ reported for 1017 observations after excluding high-risk subjects based on previous history of diabetes or CVD or TC levels $\geq 8 \mathrm{mmol} / \mathrm{l}$ ( $\sim 320 \mathrm{mg} / \mathrm{dl}$ ) or LDL-C levels $\geq 6 \mathrm{mmol} / \mathrm{l}(\sim 240 \mathrm{mg} / \mathrm{dl})$.

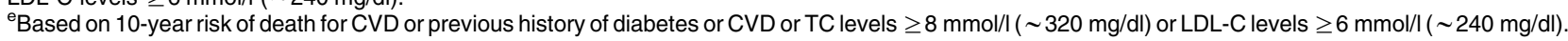

31 had LDL-C levels above $6 \mathrm{mmol} / \mathrm{l}(\sim 240 \mathrm{mg} / \mathrm{dl}))$. The proportion of subjects allocated to the high-risk group, either $a$ priori or due to an estimated 10 -year risk $\geq 5 \%$, was $26.1 \%$ and significantly higher in men $(\mathrm{OR}=2.93$, 95\% CI: 2.3-3.8). Among subjects not considered highrisk $a$ priori, the mean 10-year risk was $0.9 \%$ in women and $2.4 \%$ in men.

Overall, $84.9 \%$ (95\% CI: 82.7-86.8) of subjects had hypercholesterolemia and there was no gender difference $(\mathrm{OR}=0.93,95 \%$ CI: $0.67-1.28)$. The prevalence estimates increased significantly with age among women $(\mathrm{OR}=1.05$ per year, 95\% CI: $1.02-1.09)$ but not among men $(\mathrm{OR}=1$ per year, $95 \%$ CI: 0.97-1.04), $p($ interaction $)=0.03$.

The overall proportion of subjects eligible to receive pharmacological treatment was $29.8 \%(95 \%$ CI 27.2-32.5), higher in men than in women $(\mathrm{OR}=2.69$,
95\% CI 2.07-3.52), as shown in Table 2. The proportion increased with age $(\mathrm{OR}=1.09,95 \% \mathrm{CI} 1.07-1.11)$ and this association was stronger in women $(\mathrm{OR}=1.12,95 \%$ CI 1.09-1.15) than in men $(\mathrm{OR}=1.07,95 \% \mathrm{CI}$ $1.04-1.10), p($ interaction $)=0.01$. The variation of hypercholesterolemia prevalence and drug therapy eligibility with age categories for both genders is presented in Fig. 1.

Subjects on lipid-lowering therapy accounted for $30.4 \%$ (95\% CI: $25.7-35.4)$ of those eligible for pharmacological treatment. Overall, 9.1\% (95\% CI 7.5-10.8) of subjects were medicated with lipid-lowering drugs. Among these, 58.2\% (95\% CI 48.4-67.5) had serum lipid concentrations equal to or below the proposed threshold (primary goal). Controlled hypercholesterolemia was less frequent in men $(\mathrm{OR}=0.39,95 \%$ CI 0.17-0.87), as shown in Table 2. When adopting

Table 2 Eligibility for lipid-lowering therapy and therapeutic success, according to the European guidelines on cardiovascular disease prevention in clinical practice.

\begin{tabular}{|c|c|c|c|}
\hline$n$ & $\begin{array}{l}\text { Women } \boldsymbol{n} \text { (proportion) } \\
(95 \% \mathrm{Cl}) \\
764\end{array}$ & $\begin{array}{l}\text { Men } \boldsymbol{n} \text { (proportion) } \\
(95 \% \mathrm{Cl}) \\
\mathbf{4 5 1}\end{array}$ & $\begin{array}{l}\text { OR } \\
(95 \% \mathrm{Cl})^{\mathrm{a}}\end{array}$ \\
\hline $\begin{array}{l}\text { Eligibility for lipid-lowering therapy }{ }^{\mathrm{b}} \\
\text { Total cholesterol } \leq 4.5 \mathrm{mmol} / \mathrm{l} \text { or LDL-cholesterol } \leq 2.5 \mathrm{mmol} / \mathrm{l}\end{array}$ & $\begin{array}{l}171(22.4 \%) \\
(19.5-25.5)\end{array}$ & $\begin{array}{l}191(42.4 \%) \\
(37.7-47.1)\end{array}$ & $2.69(2.07-3.52)$ \\
\hline$n$ & 63 & 47 & \\
\hline $\begin{array}{l}\text { Therapeutic success }{ }^{c} \text { (primary goal) } \\
\text { Total cholesterol } \leq 4.5 \mathrm{mmol} / \mathrm{l} \text { or LDL-cholesterol } \leq 2.5 \mathrm{mmol} / \mathrm{l} \\
\text { Therapeutic success }{ }^{c}(\text { secondary goal) } \\
\text { Total cholesterol } \leq 4 \mathrm{mmol} / \mathrm{l} \text { or LDL-cholesterol } \leq 2 \mathrm{mmol} / \mathrm{l}\end{array}$ & $\begin{array}{l}42(66.7 \%) \\
(53.7-78.0) \\
41(65.1 \%) \\
(52.0-76.7)\end{array}$ & $\begin{array}{l}22(46.8 \%) \\
(32.1-61.9) \\
20(42.6 \%) \\
(28.3-57.8)\end{array}$ & $0.39(0.17-0.87)$ \\
\hline
\end{tabular}

${ }^{\mathrm{a} O R}$ adjusted for age, reference class: women.

${ }^{b}$ Data are presented as $n(\%)$ of subjects that are eligible for lipid-lowering therapy or are already medicated with a lipid-lowering agent.

${ }^{\mathrm{c}}$ Data are presented as $n(\%)$ of subjects medicated with a lipid-lowering agent with desirable lipid profiles. 

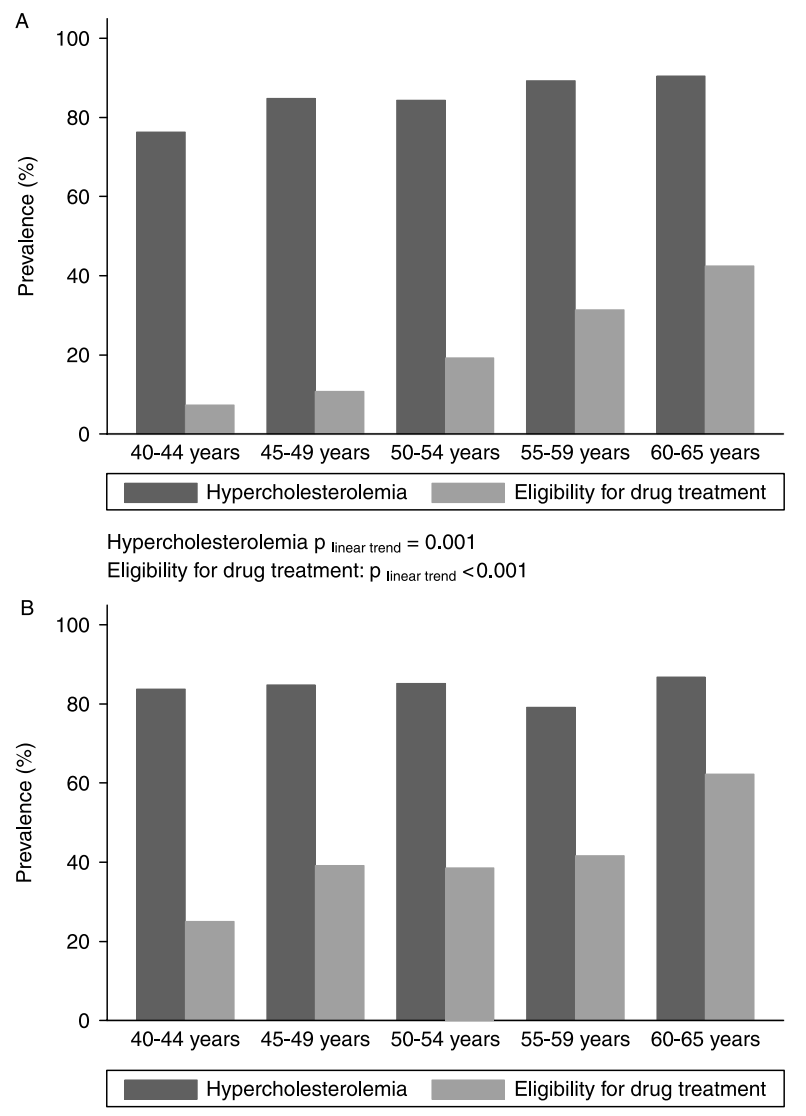

Hypercholesterolemia $p_{\text {linear trend }}=0.85$

Eligibility for drug treatment: $p$ linear trend $<0.001$

Figure 1 Hypercholesterolemia and eligibility for drug treatment among (A) women and (B) men, by age class.

the secondary goal, the proportion of control was $55.5 \%$ (95\% CI 45.7-64.9), with a similar inverse association with male gender $(\mathrm{OR}=0.35,95 \% \mathrm{CI}: 0.16-0.79)$.

\section{Discussion}

The prevalence of hypercholesterolemia in a sample of Portuguese community dwellers aged 40-65 years was $84.9 \%$. Eligibility for drug treatment was observed in $29.8 \%$ of subjects and it was higher in men than in women. Among medicated individuals, 58.2\% had serum cholesterol concentrations equal or below the primary target. Controlled hypercholesterolemia was more frequent in women.

Calibration of the SCORE low-risk charts in Spain (21) produced risk estimates $13 \%$ higher than the original low-risk function. In another low-risk country, Greece, the calibrated charts might have assigned only slightly fewer subjects to the 'high risk' category than the generic European high-risk charts (22). If the same applies to Portugal, we might be underestimating risk and, therefore, by definition, the prevalence of hypercholesterolemia.

In a systematic review on prevalence of hypercholesterolemia in Portugal (23), using the $5 \mathrm{mmol} / \mathrm{l}$ ( 190 mg/dl) TC threshold, the estimated prevalence was $64 \%$. Caution is warranted due to the heterogeneity of individual studies. The same review reported a $71 \%$ prevalence of LDL-related hypercholesterolemia, taking a $3 \mathrm{mmol} / \mathrm{l}(\sim 115 \mathrm{mg} / \mathrm{dl})$ cut-off. In the present study, the use of either TC or LDL-C to define hypercholesterolemia might have contributed to the higher figures. In a Norwegian population-based study (24), $90 \%$ of people by age 49 years would have abnormal serum cholesterol and/or blood pressure, applying the 2003 European guidelines criteria (15). However, comparisons cannot be directly drawn because, since this population is considered high risk, the corresponding SCORE risk charts were used to derive risk estimates.

Prevalence estimates increased significantly with age only among women. The less pronounced effect of age in men is explained by their higher prevalence in ages 4050 years. In this age range, there was no difference between genders in the proportion of subjects classified as high-risk a priori, in systolic blood pressure or serum TC. However, men were twice more likely to smoke leading to higher prevalence of risk estimates $\geq 5 \%$ and consequently lowering of thresholds to define hypercholesterolemia among men.

Implementing the European guidelines (15) would lead to $23.8 \%$ of patients from a primary care facility being considered eligible for lipid-lowering pharmacologic treatment in Spain (25). The proportion of subjects that were medicated at the time of the observation was lower in our study $(9.1 \%$ vs $18.4 \%)$. These differences could be explained by the healthcare centre-based sampling approach.

In a recent French survey (26), 26.8\% of medicated individuals achieved LDL-C goals according to the 2003 European guidelines (15). In the present study, treatment success rates were higher but there is still plenty of room to improve treatment effectiveness.

Some strengths and limitations of the current study ought to be addressed. The sampling process was random digit dialing in a time when ownership of line telephone was almost universal in the target population. Recruitment and data collection were protracted in time. As expected, we observed an increase in the proportion of subjects under lipid-lowering medication over time. We believe this is the most important period effect. This would only have an impact if the contribution of medicated subjects to the estimated proportions was large. Moreover, there were no major public health interventions or societal changes that would justify large variations in the hypercholesterolemia prevalence within the 5-year period. Data were available on many CVD risk factors allowing a thorough definition of high risk, despite the lack of 
assessment of microalbuminuria as specified by the guidelines. However, the proportion of participants with established CVD is underestimated not only because data on peripheral artery disease were not collected but also because stress tests were not performed for the diagnosis of CHD. Subjects in the high-risk group solely because of the predicted 10-year risk were considered eligible for treatment with lipidlowering drugs if they had blood TC or LDL-C levels above the recommended thresholds. We did not account for the 3-month period of intensive lifestyle advice proposed by the guidelines. This limitation could have led to some overestimation of hypercholesterolemia and eligibility for lipid-lowering therapy. However, we are convinced that the final balance does not result in overestimates. We did not account for drug dosages or duration of treatment to define therapeutic success, but it was not our objective to explore the determinants of therapeutic success.

The economical weight of CVD in the European health systems cannot be overemphasized. In Portugal, the costs attributable to hypercholesterolemia in the year 2000, amounted to 358.84 million Euros in direct costs and 28.31 million Euros in indirect costs (27). According to Gouveia et al. (28), in comparison with average values for Europe, the burden of ischemic heart disease was lower in Portugal, but the opposite was true for cerebrovascular disease. Overall, in Portugal, a third of CVD burden was attributable to hypercholesterolemia.

The overall awareness of dyslipidemia was low. Out of 1031 hypercholesterolemic subjects, 602 failed to mention previous history of any excess cholesterol related condition. Additionally, 14\% of subjects without hypercholesterolemia reported previous dyslipidemia (data not shown). Although caution is necessary in interpreting these results, due to the reversible nature of some lipid disorders and the fact that disorders of triglycerides were not taken into account, there are clear individual and populational implications, both in hypercholesterolemia treatment and CVD prevention. Discussing coronary risk with the patient was associated with a small but detectable improvement in the efficacy of lipid-lowering therapy (29). Communicating risk is recommended to improve adherence, along with self-monitoring and using the support of family and friends (8, 15). The physicians' role in aggressively promoting the need for lifestyle changes in all patients and using drug therapies with appropriate targeting, titration and follow-up, has become of utmost importance. However, our study demonstrates that individuals with optimal lipid profiles have become the exception. Ethical issues regarding medicalization and risk labeling of asymptomatic subjects arise. In addition to clinical outcomes, the long-term costeffectiveness of interventions to improve health in patients with hypercholesterolemia needs to be taken into account.

\section{Declaration of interest}

The authors declare that there is no conflict of interest that would prejudice the impartiality of this scientific work.

\section{Funding}

Funded by FCT (POCTI/SAU-ESP/61492/2004).

\section{References}

1 Direcção-Geral da Saúde. Risco de Morrer em Portugal, 2001. DSIA Divisão de Epidemiologia 2003 29, 45.

2 Instituto Nacional de Estatística. Estatísticas demográficas 2005. Instituto Nacional de Estatistica, 200714.

3 Gould AL, Davies GM, Alemao E, Yin DD \& Cook JR. Cholesterol reduction yields clinical benefits: meta-analysis including recent trials. Clinical Therapeutics 200729 778-794.

4 O'Regan C, Wu P, Arora P, Perri D \& Mills EJ. Statin therapy in stroke prevention: a meta-analysis involving 121000 patients. American Journal of Medicine 2008121 24-33.

5 Jenkins DJ, Kendall CW, Marchie A, Faulkner DA, Wong JM, de Souza R, Emam A, Parker TL, Vidgen E, Lapsley KG, Trautwein EA, Josse RG, Leiter LA \& Connelly PW. Effects of a dietary portfolio of cholesterollowering foods vs lovastatin on serum lipids and C-reactive protein. Journal of the American Medical Association 2003290 502-510.

6 Graham I, Atar D, Borch-Johnsen K, Boysen G, Burell G, Cifkova R, Dallongeville J, De Backer G, Ebrahim S, Gjelsvik B, HermannLingen C, Hoes A, Humphries S, Knapton M, Perk K, Priori SG, Pyorala K, Reiner Z, Ruilope L, Sans-Menendez S, Op Reimer WS, Weissberg P, Wood D, Yarnell J \& Zamorano JL. European guidelines on cardiovascular disease prevention in clinical practice: executive summary. Atherosclerosis 2007194 1-45.

7 Wilson PW, D'Agostino RB, Levy D, Belanger AM, Silbershatz H \& Kannel WB. Prediction of coronary heart disease using risk factor categories. Circulation 199897 1837-1847.

8 Executive Summary of The Third Report of The National Cholesterol Education Program (NCEP). Expert panel on detection, evaluation, and treatment of high blood cholesterol in adults (Adult Treatment Panel III). Journal of the American Medical Association $20012852486-2497$.

9 Marrugat J, D'Agostino R, Sullivan L, Elosua R, Wilson P, Ordovas J, Solanas P, Cordón F, Ramos R, Sala J, Masiá R \& Kannel WB. An adaptation of the Framingham coronary heart disease risk function to European Mediterranean areas. Journal of Epidemiology and Community Health 200357 634-638.

10 Empana JP, Ducimetiere P, Arveiler D, Ferrieres J, Evans A, Ruidavets JB, Haas B, Yarnell J, Bingham A, Amovyel P \& Dallongeville J. Are the Framingham and PROCAM coronary heart disease risk functions applicable to different European populations? The PRIME Study European Heart Journal 200324 1903-1911.

11 Laurier D, Nguyen PC, Cazelles B \& Segond P. Estimation of CHD risk in a French working population using a modified Framingham model. The PCV-METRA Group. Journal of Clinical Epidemiology 199447 1353-1364.

12 Bastuji-Garin S, Deverly A, Moyse D, Castaigne A, Mancia G, de Leeuw PW, Ruilope LM, Rosenthal T \& Chatellier G. The Framingham prediction rule is not valid in a European population of treated hypertensive patients. Journal of Hypertension 200220 1973-1980.

13 Menotti A, Puddu PE \& Lanti M. Comparison of the Framingham risk function-based coronary chart with risk function from an Italian population study. European Heart Journal 200021 365-370.

14 Conroy RM, Pyorala K, Fitzgerald AP, Sans S, Menotti A, De Backer G, De Bacquer D, Ducimetière P, Jousilahti P, Keil U, Njolstad I, Oganov RG, Thomsen T, Tunstall-Pedoe H, Tverdal A, Wedel H, Whincup P, Wilhelmsen L \& Graham I. Estimation of tenyear risk of fatal cardiovascular disease in Europe: the SCORE project. European Heart Journal 200324 987-1003. 
15 De Backer G, Ambrosioni E, Borch-Johnsen K, Brotons C, Cifkova R, Dallongeville J, Ebrahim S, Faergemen O, Graham I, Mancia G, Cats VM, Orth-Gomér K, Perk K, Pyorala K, Rodicio JL, Sans S, Sansoy V, Sechtem U, Silber S, Thomsen T \& Wood D. European guidelines on cardiovascular disease prevention in clinical practice: third joint task force of European and other societies on cardiovascular disease prevention in clinical practice (constituted by representatives of eight societies and by invited experts). European Journal of Cardiovascular Prevention and Rehabilitation 200310 S1-S10.

16 Ramos E, Lopes C \& Barros H. Investigating the effect of nonparticipation using a population-based case-control study on myocardial infarction. Annals of Epidemiology 2004 14 437-441.

17 Allain CC, Poon LS, Chan CS, Richmond W \& Fu PC. Enzymatic determination of total serum cholesterol. Clinical Chemistry 1974 20 470-475.

18 Bucolo G \& David H. Quantitative determination of serum triglycerides by the use of enzymes. Clinical Chemistry 197319 476-482.

19 Warnick GR \& Albers JJ. A comprehensive evaluation of the heparin-manganese precipitation procedure for estimating high density lipoprotein cholesterol. Journal of Lipid Research 197819 65-76.

20 Friedewald WT, Levy RI \& Fredrickson DS. Estimation of the concentration of low-density lipoprotein cholesterol in plasma, without use of the preparative ultracentrifuge. Clinical Chemistry 197218 499-502.

21 Sans S, Fitzgerald AP, Royo D, Conroy R \& Graham I. Calibrating the SCORE cardiovascular risk chart for use in Spain. Revista Española de Cardiología 200760 476-485.

22 Panagiotakos DB, Fitzgerald AP, Pitsavos C, Pipilis A, Graham I \& Stefanadis C. Statistical modelling of 10-year fatal cardiovascular disease risk in Greece: the HellenicSCORE (a calibration of the ESC SCORE project). Hellenic Journal of Cardiology 200748 55-63.
23 Costa J, Borges M, Oliveira E, Gouveia M \& Carneiro AV. Incidence and prevalence of hypercholesterolemia in Portugal: a systemic review. Part II. Revista Portuguesa de Cardiologia 200322 683-702.

24 Getz L, Kirkengen AL, Hetlevik I, Romundstad S \& Sigurdsson JA. Ethical dilemmas arising from implementation of the European guidelines on cardiovascular disease prevention in clinical practice. A descriptive epidemiological study. Scandinavian Journal of Primary Health Care 200422 202-208.

25 Buitrago F, Canon-Barroso L, Diaz-Herrera N, Cruces-Muro E, Escobar-Fernandez M \& Serrano-Arias JM. Comparison of the REGICOR and SCORE function charts for classifying cardiovascular risk and for selecting patients for hypolipidemic or antihypertensive treatment. Revista Española de Cardiología 2007 60 139-147.

26 Van Ganse E, Laforest L, Burke T, Phatak H \& Souchet T. Mixed dyslipidemia among patients using lipid-lowering therapy in French general practice: an observational study. Clinical Therapeutics 200729 1671-1681.

27 Gouveia M, Borges M, Costa J, Oliveira E, David C \& Carneiro AV. Costs of illness due to hypercholesterolemia in Portugal. Revista Portuguesa de Cardiologia 200423 1037-1054.

28 Gouveia M, Borges M, Costa J \& Carneiro AV. Burden of disease from hypercholesterolemia in Portugal. Revista Portuguesa de Cardiologia 200423 255-270.

29 Grover SA, Lowensteyn I, Joseph L, Kaouache M, Marchand S, Coupal L \& Boudreau G. Patient knowledge of coronary risk profile improves the effectiveness of dyslipidemia therapy: the CHECK-UP study: a randomized controlled trial. Archives of Internal Medicine $20071672296-2303$.

Received 16 August 2008

Accepted 10 September 2008 